\title{
Os fluidos limites do corpo. Reflexões sobre saúde indígena no leste de Roraima
}

\section{Giovana Acacia Tempesta}

\section{(2) OpenEdition \\ 1 Journals}

Edição electrónica

URL: http://journals.openedition.org/aa/798

DOI: $10.4000 /$ aa.798

ISSN: 2357-738X

Editora

Programa de Pós-Graduação em Antropologia Social (UnB)

\section{Edição impressa}

Data de publição: 1 junho 2010

Paginação: 129-148

ISSN: 0102-4302

\section{Refêrencia eletrónica}

Giovana Acacia Tempesta, «Os fluidos limites do corpo. Reflexões sobre saúde indígena no leste de Roraima», Anuário Antropológico [Online], v.35 n. 1 | 2010, posto online no dia 08 outubro 2015, consultado o 28 abril 2021. URL: http://journals.openedition.org/aa/798 ; DOI: https://doi.org/ 10.4000/aa.798

\section{(c) (i) (9)}

Anuário Antropológico is licensed under a Creative Commons Atribuição-Uso Não-Comercial-Proibição de realização de Obras Derivadas 4.0 International. 


\section{Os fluidos limites do corpo. Reflexões sobre saúde indígena no leste de Roraima}

Giovana Acacia Tempesta

CGID/FUNAI

De modo geral, os povos indígenas na América do Sul apresentam concepções complexas sobre pessoa, corporalidade, doença, saúde e morte, as quais dificilmente encontram correspondentes no campo da medicina ocidental, compreendida como um conjunto de práticas, saberes e instituições que visa ao restabelecimento da saúde do indivíduo e que se tornou hegemônico no mundo ocidental no século XIX. No Brasil, a Constituição Federal de 1988 assegurou aos indígenas o direito culturalmente diferenciado de atendimento à saúde, e leis adicionais determinaram as diretrizes de atuação do órgão responsável pela "saúde indígena" dentro e fora das aldeias. Em que pese o caráter humanista da legislação, na prática a interação entre profissionais de saúde e povos indígenas está sujeita a todo tipo de equívocos. Nesse sentido, proponho pensar alguns limites e possibilidades da extensão da medicina aos povos indígenas a partir do caso etnográfico dos Wapichana e Macuxi que vivem na área de "lavrado" do estado de Roraima.

Durante minha pesquisa de campo numa aldeia wapichana e macuxi, ${ }^{1}$ presenciei visitas da equipe médica municipal, encarregada de tratar as doenças mais comuns na aldeia, como verminoses, pressão alta, tuberculose, malária e problemas dermatológicos. Nas situações de consulta, no interior do pequeno posto de saúde, as relações de poder entre médico e paciente ganhavam contornos tensos, com profissionais proferindo diagnósticos com base em duas ou três perguntas genéricas que exprimiam o verdadeiro abismo entre as duas cosmologias em contato. Todavia, após a retirada dos profissionais de saúde, um cenário intrincado de ressignificação cultural evidenciava-se na aldeia. Diagnósticos eram debatidos com parentes, questionados e inseridos no sistema local de cura, combinados a remédios tradicionais, sessões de reza e xamanismo, assim como os fármacos tinham alteradas a dosagem e a indicação prescritas pelo médico, para se conformarem à concepção wapichana/macuxi de fisiologia. Assim, por exemplo, uma pomada indicada para problemas ginecológicos era utilizada para curar feridas purulentas na pele, "porque a pomada", explicou-me uma mulher macuxi, "é fria”, ideal para neutralizar 
o "calor" do processo inflamatório. A procura seletiva por medicamentos alopáticos, bem como a "subversão" das receitas médicas revelam que os Wapichana e os Macuxi têm muito interesse pelos fármacos, embora esse "interesse" nem sempre coincida com o dos profissionais de saúde.

Outra prática comum era a utilização de anti-helmínticos segundo o critério indígena de "força": um remédio era considerado tanto mais poderoso quanto mais escura fosse a sua cor. Além disso, esperava-se que os anti-helmínticos provocassem vômito, para "desintoxicar" de modo mais eficiente o corpo doente, procedimento que condiz com as ideias indígenas sobre expulsão do agente etiológico do corpo da vítima de feitiçaria. De sua parte, como ignoravam os usos singulares que os Wapichana e os Macuxi faziam dos remédios industrializados, os profissionais de saúde não compreendiam os resultados por vezes inócuos dos tratamentos que ministravam, e atribuíam tal fato à suposta ignorância dos pacientes, sem jamais questionarem sua própria prática; mesmo os profissionais de saúde mais sensíveis tinham dificuldade em dialogar com os indígenas e em aceitar a legitimidade das suas ideias de saúde e doença.

Para concluir essa breve relação de desencontros interculturais, lembro que as mulheres no Pium estão preferindo dar à luz em hospitais na cidade, apontando como justificativa a menor intensidade das dores, obtida mediante anestesia, e a maior rapidez na recuperação após o parto. O grande problema para os indígenas é o cardápio do hospital, que inclui alimentos "reimosos", como o feijão, que as mulheres em resguardo não podem ingerir. ${ }^{2}$

É importante mencionar, porém, que em nível nacional há tentativas de compatibilização do sistema de saúde oficial com o sistema tradicional, as quais buscam engajar as parteiras e os pajés nos tratamentos dos doentes e nos trabalhos de capacitação dos agentes indígenas de saúde (AIS). ${ }^{3}$ Uma das dificuldades nesse terreno é o fato cultural de que os AIS ocupam uma posição delicada diante da comunidade, uma vez que os medicamentos industrializados são inseridos no circuito local de reciprocidade. Como a generosidade é o maior valor social para os Wapichana e os Macuxi, negar aos pacientes a quantidade de remédios que eles solicitam (em geral, muito superiores à prescrição médica) rende ao AIS acusações de mesquinharia e, no limite, rumores sobre a prática de feitiçaria.

O contexto do Pium pode vir a assemelhar-se ao que Follér (2004) chama de "intermedicalidade", uma zona de contato entre diferentes tradições médicas em que ocorrem negociações do conhecimento e da identidade étnica e se produz uma medicina híbrida. A partir da perspectiva da conjugação de conhecimento e poder, a medicina ocidental é pensada como um tipo de saber associado a uma ideologia específica. Nesse sentido, Follér indica que os Shipibo-Conibo (Peru) distinguem 
entre "medicina biomédica" e poder biomédico, no âmbito de "um projeto de negociação e renegociação, resistência cultural e ilustração da formação de uma identidade indígena como estado dinâmico e transitório" (Follér, 2004:144). A recusa dos indígenas à hegemonia da medicina ocidental (e à autoridade dos médicos) não se confunde, portanto, com a recusa a certos medicamentos ou tratamentos considerados adequados para algumas doenças, desde que não enfraqueçam o "sistema de saúde" indígena.

Proponho que os muitos desencontros entre a medicina ocidental e a medicina indígena podem ser superados em favor do estabelecimento de um diálogo intercultural, mas para isso é necessário um esforço para inserir a forma atual como os Wapichana e os Macuxi se relacionam com a estrutura de saúde estatal no horizonte mais amplo de sua complexa cosmologia e da história da colonização na região.

\section{Novos tempos, novos corpos?}

Os Wapichana e os Macuxi, ao lado dos Taurepang, Patamona, Ingarikó e Sapará, habitam tradicionalmente o leste do estado de Roraima, que compreende uma porção de campos (lavrado) e uma região de serras. Atualmente, esses povos vivem em 28 Terras Indígenas (Ricardo 2006). Os Macuxi e os Wapichana são maioria numérica no estado e, nas duas últimas décadas, têm formado várias aldeias "mistas" no lavrado. Os Macuxi, grupo de filiação linguística carib, somam aproximadamente 19 mil indivíduos, a grande maioria vivendo em território brasileiro (principalmente entre os rios Surumu e Maú, nas serras), com algumas aldeias na Guiana (Santilli, 1994, 2001). Os Wapichana são um grupo de língua aruak que contabiliza aproximadamente 5 mil pessoas do lado brasileiro e 6 mil pessoas na Guiana. No Brasil, seu território tradicional estende-se pelos vales dos rios Tacutu e Uraricoera (Farage, 1997; Forte, 1990). ${ }^{4}$

Ao longo do século XX, consolidou-se uma pequena elite local no leste de Roraima, voltada para a formação de grandes latifúndios monocultores; devido a seu grande poder de pressão, a demarcação de Terras Indígenas, iniciada nos anos 80, produziu "ilhas" de indígenas em meio às fazendas, gerando uma situação de conflito latente. Para fazer frente a esta situação de confronto interétnico, nos anos 1970 os indígenas da região das serras começaram a se organizar em torno das lideranças indígenas anteriormente instituídas pelas agências indigenistas, os tuxauas. Com apoio da igreja católica, deram início às assembleias de tuxauas nas serras, que levaram à criação do Conselho Indígena de Roraima (CIR), o qual, nos anos 90, passou a expandir sua área de atuação para o lavrado. Foram instituídos conselhos 
políticos regionais, que organizaram o leste de Roraima em "etnorregiões" (termo usado pelos indígenas), atualmente em número de oito: Serras, Baixo Cotingo, Raposa, Surumu (subdividida em alto, médio e baixo), São Marcos, Amajari, Taiano e Serra da Lua.

Desde os anos 90, também a escola vem se configurando como importante instrumento de intervenção social para os indígenas em Roraima. Os professores indígenas proferem um discurso de revigoramento das tradições, e desempenham um papel político de destaque nas aldeias; eles têm sua própria organização, a OPIR, que atualmente vem debatendo a questão da educação culturalmente diferenciada e a necessidade de adaptação da escola à realidade das aldeias. De sua parte, as mulheres criaram uma organização própria, a OMIR, para tratar de temas que dizem respeito à família, como as consequências do consumo excessivo de bebida alcoólica nas aldeias. Tal investimento em organização política - na qual a saúde ocupa papel de destaque - explicita um projeto de resistência cultural admirável que não deixa, contudo, de formular uma crítica às consequências negativas do contato. Assim, os velhos e os jovens wapichana e macuxi com quem conversei idealizam um passado de fartura, saúde e harmonia, que opõem a um presente ambivalente, em que os ganhos materiais e políticos convivem com a alteração de costumes e crenças tradicionais e com transformações nos corpos das pessoas.

Os Wapichana e os Macuxi distinguem o índio "brabo" do índio "manso", "civilizado": "Tem o índio brabo, aquele que vive sem roupa, no mato, o Yanomami, e o índio manso, que sabe conversar, que conhece o dinheiro, que conhece branco, que somos nós, os Wapichana, os Macuxi", diziam meus interlocutores. O termo "civilizado" guarda aí uma ambivalência, pois se os Wapichana e os Macuxi apropriamse de elementos do mundo dos não-índios, fazem-no apenas para melhor resistir, enquanto grupos étnicos diferenciados, às ameaças de desapropriação de terras e às violências que vêm sofrendo há séculos. Nesse sentido, empenham-se em transformar tudo aquilo que aprendem e obtêm na relação com o não-índio e suas instituições (a saber: escola, igrejas católica e protestante, Funai, ONGs nacionais e internacionais, missionários, agências de financiamento de projetos) em benefícios para suas "comunidades".

Os indígenas no Pium mostravam grande interesse em conversar sobre resguardos, tema de minha pesquisa, bem como sobre o campo mais amplo da corporalidade, o que inclui a questão da "saúde indígena". Falas como a transcrita abaixo, que me foram dirigidas inúmeras vezes, me fizeram compreender a dimensão política do tema, isto é, a crítica indígena ao contato que subjaz ao discurso sobre a pessoa, o corpo, a saúde e a doença. 
Ela tem não sei quantos anos já; no tempo de menstruação dela, não vem muito [sangue], vem só um pouquinhozinho, agora eu não, como eu sou de geração de agora, já é diferente, já no meu “tempo" vem muito sangue, porque eu não guardo direito os meus resguardos, né? Quando eu ganho nenê, já vou tomando café, chá, doce. Aí o que acontece? Só dá isso aí, doença pra gente; hoje em dia, a gente mesmo está fazendo doença pra gente, trazendo doença mesmo. Eu não tomo mais mingau morno. Quando eu tomo: “Ai, tá quente!”. Eu não tenho mais costume. Quando eu vou banhar: “Ai, mamãe, tá quente!”. Aí quando ela vai me banhar com água morna: “Tá quente, tá bom, já chega!”. Ela não, ela tem que banhar, é um panelão assim, enche todinho, é um panelão cheio ou um camburão, quente, aquele vapor mesmo saindo. Pra não dar cólica depois. É isso daí. Hoje, ela nunca ficou doente. Ela guardou bem. Agora eu, não; eu sou nova, mas sou toda dolorida, não aguento nada, né? Por quê? Porque não tomo banho [morno], não faço resguardo bem. Até com duas semanas já faço o gosto do marido. Elas [as antigas] não, elas guardam até! É isso o que ela está dizendo: "Eu que já estou vovó e nunca senti”. Ela carrega peso, carrega muito peso, ela nunca sentiu assim dor, por isso, porque ela guardou o resguardo dela direitinho, desde o começo até o final (Janaína, 35 anos, traduzindo e comentando as palavras em wapichana de sua mãe, Sílvia, 60 anos, Pium, 08/06/03). ${ }^{5}$

Pode se depreender das palavras de Janaína e Sílvia que o corpo forte, resistente à dor e apto ao trabalho braçal, que conhece a liberação moderada de sangue menstrual, é correlato de uma época passada em que as mulheres observavam os resguardos de menstruação e parto. Nos dias atuais, ao contrário, as mulheres teriam deixado de fazer resguardo e se tornado mais fracas. Se esse discurso não corresponde exatamente à prática - afinal, muitas mulheres, inclusive jovens, ainda praticam resguardo - ele revela, contudo, o sentimento de responsabilidade pela transformação do próprio corpo. A ideia de que "hoje em dia a gente mesmo está fazendo doença pra gente” exprime um princípio cosmológico segundo o qual a ampla gama de males que afligem os Wapichana e os Macuxi é produto da ação dos próprios humanos, quando deixam de agir como se deve.

Assim, a destruição da pessoa, no sentido de doença e morte, tem três causas principais: o ataque por parte dos "bichos", a transformação em kanaimé e o feitiço. Não apenas as causas e os tratamentos das doenças são elaborados de modo singular pelos Wapichana e os Macuxi, como também as próprias noções de saúde e doença.

Em primeiro lugar, examinemos as aflições causadas aos humanos pelos "bi- 
chos", especialmente no caso de mulheres menstruadas. "Bicho" é o nome que os indígenas dão aos entes "sobrenaturais", aos "espíritos" e aos duplos de tudo o que há no mundo, sejam pessoas, seres da natureza ou objetos manufaturados (na língua wapichana, são os panaokarunao). ${ }^{6}$ Uma mulher menstruada deve cumprir resguardo, o que significa, basicamente, abster-se de uma lista de alimentos e de atividade sexual, ficar reclusa, não tocar nos instrumentos de caça e pesca de qualquer homem ou cozinhar. A dieta da mulher menstruada exclui os alimentos "reimosos", os classificados como "doces" e "azedos", os muito salgados, a pimenta, o leite e os ovos.

O leite e os alimentos classificados como "doces", "azedos" e salgados fazem coagular o sangue, produzindo cólicas (entendidas como um obstáculo ao sangramento normal), sendo que a ingestão de frutas como a ata (fruto da família das anonáceas) ainda provoca corrimento vaginal, e os ovos acabam por corromper ainda mais o sangue menstrual, intensificando o mau odor (“pitiú") que já o caracteriza. Por sua vez, a ingestão de alimentos salgados provoca hemorragia. As restrições alimentares que se aplicam à mulher durante o resguardo de menstruação visam evitar problemas de saúde na velhice, bem como dificuldades relativas à fertilidade; além disso, tais restrições vinculam-se a uma concepção própria sobre fisiologia que exprime a valoração negativa do excesso de sangue no corpo e de seu odor pronunciado. Com efeito, o cheiro que os Wapichana e os Macuxi atribuem ao sangue menstrual é o cheiro "podre", "forte", "ruim”, o apodrecimento surgindo como signo de corrupção do corpo, remetendo simbolicamente à morte.

O resguardo de menstruação implica igualmente um imperativo moral. Porque o sangue menstrual é uma substância ambígua, a um só tempo criativa e destrutiva, ${ }^{7}$ essencialmente poderosa e poluente, as mulheres menstruadas devem ocultá-lo, demonstrando assim autocontrole e responsabilidade para com os corresidentes. Ocorre que a conjunção simbólica de mulher menstruada ou sangue menstrual com os utensílios de trabalho de um homem acarreta panema ${ }^{8}$ para ele. Um homem "empanemado" tem azar nas pescarias e nas caçadas, fica "preguiçoso", apático, sem disposição para as atividades normais, incluindo o sexo. A panema não é exatamente uma patologia, mas pode se dizer que integra o rol das aflições mais importantes conhecidas pelos Wapichana e os Macuxi, na medida em que interrompe o ciclo de trocas alimentares que movimenta a vida social na aldeia e, no limite, também a produção de filhos (o homem empanemado não deseja/não consegue ter relações sexuais).

Mulheres que infringiram o resguardo de menstruação são responsabilizadas, de modo genérico, pela decadência das aldeias; afirma-se que sua presença nefasta corrompe roças e pomares. Desta perspectiva, a podridão do corpo da mulher menstruada é contagiosa e leva à desordem física, social, cósmica. Assim, concor- 
dando com a análise de M. Douglas (1966), essas ideias de separação, purificação, demarcação de limites e punição a transgressões têm a função de impor sistematicidade à experiência humana, necessariamente desordenada, indicando que a reclusão a que as mulheres menstruadas estão sujeitas destina-se a marcar, moral e simbolicamente, um momento do ciclo vital considerado importante e perigoso pelos Wapichana e os Macuxi.

Por seu turno, as restrições de atividade têm por finalidade poupar a mulher menstruada do ataque dos "bichos", que se sentem "ofendidos" pelo odor do sangue menstrual e agridem as mulheres que se aventuram a passear nas proximidades de rios e igarapés. Esses "bichos" engravidam as infratoras, mas se trata de uma gravidez anômala, caracterizada por sinais de doença fatal; os "bichos" podem ainda propor casamento às mulheres, levando-as para morar com eles no mundo subaquático - e isto, do ponto de vista humano, significa morrer. Tudo se passa como se os "bichos" enxergassem a mulher menstruada, que está perdendo sangue e fica pálida, como enxergam a si mesmos, e tentassem se relacionar com ela como se fosse um dos seus. É interessante notar que a aparência de todas as espécies de "bichos" é o inverso da aparência das pessoas saudáveis. A cor branca que caracteriza vários desses "bichos" indica uma aparência oposta àquela que devem exibir os seres humanos saudáveis, sendo a palidez (ou translucidez) apontada como indício de doença, associada à fraqueza.

Temos aqui uma cosmologia que pode ser pensada à luz da teoria do perspectivismo ameríndio, sistematizada por E. Viveiros de Castro (2002), de acordo com a qual cada perspectiva ou ponto de vista é sinônimo de diferença e está sediada no corpo. Nesses termos, se "os corpos são o modo pelo qual a alteridade é apreendida como tal" (idem:381) e "a morfologia corporal é um signo poderoso dessas diferentes afecções (e capacidades)" (idem:380), pode se compreender melhor o esforço dos Wapichana e dos Macuxi em se mostrarem plenamente humanos para os "bichos", e também para os corresidentes.

Uma segunda fonte de perigo para os humanos é o kanaimé, definido pelos indígenas como "gente que virou bicho". Um forasteiro recém-chegado a uma aldeia no lavrado rapidamente será informado dos perigos de andar sozinho à noite por lugares desabitados. Os Wapichana e os Macuxi no Pium me contavam, num tom aterrador, que os kanaimés ou "rabudos" desfiguram o corpo de sua vítima, introduzem-lhe folhas no ânus e nos órgãos genitais, furam-lhe a língua, cortam-lhe o ventre, quebram-lhe os membros e o pescoço, sugam o pus de suas feridas como se bebessem caxiri. ${ }^{9}$ Essa modalidade de devoração pode ser vista apenas pelo pajé, 
que percebe as articulações rompidas e as folhas colocadas sob as unhas ou dentro dos orifícios corporais da vítima. Os kanaimés agem depois que o sol se põe, andam em bandos e se escondem na mata, assoviando para atrair suas vítimas; em geral, assumem a forma de tamanduá-bandeira, cuja carne é tabu para os indígenas. $\mathrm{O}$ assovio empregado em lugar da linguagem articulada foi interpretado por N. Farage (1997) como a forma extrema da vingança, um sentimento que não pode ser comunicado; por isso, o silêncio de uma pessoa (recusa de conversar) é sinal de alerta para os Wapichana e os Macuxi.

Por outro lado, quando avistam alguém solitário, principalmente se estiver se alimentando, os indígenas gritam jocosamente: “Olha o kanaimé!”. Tanto quanto o silêncio de uma pessoa, a solidão e a mesquinharia alimentar são alvo da reprovação dos Wapichana e dos Macuxi. É interessante notar que os kanaimés não existem apenas nas aldeias em Roraima. Ao contrário, os Wapichana e os Macuxi explicam os assassinatos violentos ocorridos em Boa Vista como ataques de kanaimés, ou seja, kanaimés aparecem predominantemente em lugares despovoados ou superpopulosos, e são raros em aldeias de tamanho médio, algo em torno de 150 pessoas, o que parece ser o ideal "sociológico" wapichana/macuxi.

No entanto, a transformação em kanaimé é reversível. Diz-se que muitos kanaimés são "homens perfeitos" durante o dia, que durante a noite assumem a forma de "bicho" e viajam por longas distâncias para fazer o mal. Nesse sentido, "gente que virou bicho” parece ser uma fórmula que exprime a reversibilidade da condição humana, e que acena para a metamorfose como possibilidade concreta num universo cosmológico em que a pessoa é concebida como uma posição de instabilidade entre outros modos de ser - animais, vegetais, objetos, "bichos" (Viveiros de Castro, 2002). O comportamento de uma pessoa que se comporta como "bicho", isto é, que desrespeita as regras sociais e se distancia da condição humana, adquire sentido no campo simbólico da alimentação. A devoração, concebida como forma de antialimentação, surge assim como a ação mais ameaçadora do ideal de vida comunitária e da pessoa mesma. Em artigo sobre comensalidade e canibalismo, C. Fausto (2002) afirma que, no contexto amazônico, "não comer como e com é recusar o aparentamento, e tal recusa equivale a se colocar na posição de inimigo" (Fausto, 2002:15). A partir desta perspectiva, o kanaimé pode ser lido como a hipérbole do comportamento antissocial, na medida em que corporifica a negação do componente relacional da alimentação.

Mas não apenas os "bichos" e os kanaimés ameaçam os humanos. A feitiçaria, a terceira forma de destruição da pessoa a ser apresentada aqui, é uma ação negativa contra humanos praticada pelos próprios humanos. Se nas refeições cotidianas e 
nos momentos de resguardo criam-se ou reafirmam-se o sentimento de pertença à coletividade e a conformação à medida humana, o isolamento indica a recusa à vida em sociedade. Dentro desta terceira modalidade de destruição da pessoa, encontramos corresidentes que, embora não "virem bicho", exibem um comportamento a-social. Os feiticeiros são notadamente descritos como sovinas e invejosos, não participam das festas e reuniões políticas da aldeia, isolam-se em suas casas, podendo apresentar traços físicos considerados anormais, como um olhar demasiado penetrante ou uma deficiência motora. Em geral, os Wapichana e os Macuxi desconfiam de pessoas mesquinhas e reservadas, pois elas podem estar tramando algo contra os corresidentes. Para eles, a mesquinharia é concebida como expressão de hostilidade, como negação da troca que institui a socialidade. No limite, o feiticeiro é um estrangeiro, é alguém com quem não há comunicação possível; a feitiçaria é percebida como a criação indesejável de “outros" no interior da aldeia, e abominada como séria ameaça à vida comunitária.

Os Wapichana e os Macuxi dizem que uma pessoa foi enfeitiçada quando, subitamente, perde o apetite, fica triste, perde o ânimo para as atividades cotidianas, apresenta diarreia ou vômito incessante, sinais inequívocos de que a "alma"10 da pessoa está se desligando do corpo. Caso recordem algum contato com pessoas de fora da família nuclear, suspeitam logo de "olho gordo" ou envenenamento, sendo que parentes afins são frequentemente acusados de feitiçaria. Nos casos mais crônicos, um pajé é acionado. Espera-se dele que descubra a causa da enfermidade, restabeleça a ligação entre "alma” e corpo e, em caso de confirmação da hipótese de feitiço, que faça retornar o mal à sua fonte. Por isso, diz-se que os feiticeiros adoecem com frequência, em razão do próprio mal que praticam. Seguramente, as acusações de feitiçaria são o idioma para verbalizar os conflitos e as tensões latentes na aldeia; no Pium, alguém taxado de feiticeiro dificilmente seria eleito tuxaua, por exemplo. Neste sentido, o medo de ser chamado de feiticeiro incentiva as pessoas a exibirem comportamentos socialmente aprovados.

Em casos de feitiçaria, assim como em casos de quebra de resguardo ou ataque de "bichos", deve se acionar um pajé o mais rápido possível. Se no geral os homens são os responsáveis pelas doenças, alguns deles, por outro lado, são capazes de reverter a situação de sofrimento. Em linhas gerais, o xamanismo visa à cura do doente com base na reafirmação dos laços de parentesco, compadrio e solidariedade aldeã. As sessões xamânicas combinam administração de "garrafadas" (compostos de plantas medicinais e aguardente), banhos terapêuticos, rezas, bater de folhas e exortações dos parentes e amigos do paciente, os quais declaram veementemente o carinho que sentem pelo doente, reforçando sua responsabilidade sobre ele. 
Nesse momento, o pajé trava dura batalha invisível com os "espíritos", pois, quando a "alma" se afasta do corpo e, portanto, do mundo dos viventes, torna-se alvo das tentativas de sedução dos espectros dos mortos (em wapichana: ma'chai, uma classe de panaokarunao, cf. Farage, 1997), que oferecem alimentos e fazem propostas de cunho sexual para o doente, de modo a atraí-lo para o mundo dos "sobrenaturais". Ao pajé cabe ainda incentivar os parentes e os amigos a convencerem a "alma" do doente a permanecer no mundo dos vivos, bem como, posteriormente, relembrar ao convalescente as regras de comportamento sancionadas.

Estas são as coordenadas simbólicas gerais de uma espécie de economia política do sangue e outras substâncias corporais pautada por ideias mais amplas sobre o cosmos. Tal economia política serve à regulação das entradas e das saídas, no corpo humano, de sangue, sêmen, gordura, fezes, urina, suor e lágrimas, e zela pela manutenção da substância vital nos limites do corpo, enfim, pela manutenção da pessoa nos limites da condição humana. Tem-se, pois, que a "saúde" para os Wapichana e os Macuxi manifesta-se sob a forma de um corpo forte, belo, corado, ágil, desenvolto, capaz de desempenhar as funções adequadas à idade, ao gênero e ao status social da pessoa; trata-se, assim, de um corpo "em processo". A esta noção de corpo, concebida pelos indígenas como diferente do corpo dos não-índios, corresponde uma noção de saúde que focaliza a regulamentação ou o controle do fluxo de substâncias.

Diante do exposto, compreende-se melhor a distinção cunhada pelos Wapichana e os Macuxi entre "doenças de branco", aquelas que podem ser curadas com fármacos, e “doenças de índio”, contra as quais os remédios industrializados são absolutamente ineficientes. Certa vez, uma mulher wapichana me explicou o seguinte:

Se hoje você está com fome, aí você vai lá pra roça com fome, sem botar uma pimentinha na boca, sem comer um mingauzinho, você vai sair com o estômago seco, por ali, sol quente, você já vai voltando com o estômago vazio, por ali ma'chai já encontra a senhora, esse espírito que morre, espírito mau da pessoa, já dá comida pra senhora, porque está vendo a senhora; ele vê, a gente não o vê, mas ele vê a gente, ele chega com o vento: não tem esse redemoinho? [...] Quanto mais dá remédio, o remédio vai prejudicando você, porque não era pra isso. O médico nem sabe o que é, ele dá vitamina, não era nem pra isso. Tem um lado também para o médico, tem doença para o médico e doença para o pajé. É por isso que médico mata muita gente, né? Porque, às vezes, adoeceu, vai embora para o hospital, não procura marinao [xamã, em wapichana], procura o hospital 
e pronto, chega lá, o médico passa tanto remédio, não é nem para o médico, às vezes, aí acaba matando a pessoa (Janaína, 35 anos, Pium, 08/06/03).

\section{Sobre como são formadas as pessoas}

Entre os Wapichana e Macuxi, os resguardos de menstruação e de parto - ao lado dos resguardos de doença e de luto, que não serão analisados aqui - constituem um importante conjunto de práticas de aparentamento que exprimem, diariamente, a responsabilidade dos parentes consanguíneos pelo bem-estar uns dos outros. A aldeia é concebida como agrupamento de semelhantes que se contrapõe a um universo de Outros - estrangeiros, entes “sobrenaturais", mortos - com quem não se pode viver bem; na aldeia o parentesco é criado pelo fluxo cotidiano de comida e bens. Assim, o domínio da intimidade doméstica, onde têm lugar as refeições, o parto, a amamentação e a educação dos filhos, surge como a esfera propriamente social, em meio a um universo cosmológico co-habitado por espécies animais e vegetais e "bichos" que podem ser nocivos aos humanos. ${ }^{11}$

De acordo com esta visão de mundo, ser humano não é um fato natural ou ontológico imutável; manter-se dentro dos limites da condição humana é antes um esforço continuado, um processo permanente. Isto nos remete ao conceito de "socialidade", um termo empregado em trabalhos de "antropologia do cotidiano" que designa um ideal de harmonia social baseado na generosidade, apanágio do propriamente humano (Overing \& Passes, 2000). A socialidade, processo contínuo e dinâmico que coincide com a construção e a manutenção de laços de parentesco, em nível local, articula-se ao sentimento de estar relacionado a outras pessoas (relatedness), e também à aptidão propriamente social/cultural das pessoas (agency ou agência) (ver McCallum, 1998; Strathern, 1995, 1997). A partir desta perspectiva, ação é relação, e relação é a própria sociedade em movimento, pois todos os atos de uma pessoa incidem sobre a rede de dependências mútuas em que ela existe socialmente.

De acordo com sua concepção coletivista do ciclo vital, os Wapichana e os Macuxi acreditam que a saúde de uma pessoa depende da atualização de diferentes laços sociais, em geral cifrados em relações de parentesco, os quais também aparecem como um comentário político à vida em sociedade. O exemplo do alcoolismo é interessante. O lema de uma campanha recentemente organizada pelo CIR e pela OMIR era: "Não ao alcoolismo, sim à comunidade", frase que sintetiza o pensamento segundo o qual o bem-estar de cada pessoa depende do bem-estar da coletividade, e vice-versa.

Se for possível falar num ideal de vida aldeã, eu diria que, para os Macuxi e os Wapichana, a harmonia coincide com demonstrações reiteradas de controle das 
emoções, de generosidade e de satisfação com a vida comunitária, além do respeito às normas estabelecidas, sobretudo aquelas relativas à alimentação. Nesse sentido, os preceitos da chamada "antropologia do cotidiano", baseada em etnografias sobre povos amazônicos (ver a coletânea organizada por Overing \& Passes, 2000), constituíram um bom ponto de partida para minhas observações. ${ }^{12}$ Este importante aporte teórico-metodológico, contudo, não sustenta uma reflexão aprofundada sobre relações interétnicas, e é para este tema que é preciso se voltar a fim de tentar compreender as concepções indígenas sobre doença e saúde.

Observa-se, pois, que a pessoa, nesse contexto, difere radicalmente do indivíduo do pensamento ocidental moderno, foco da medicina alopática. Os profissionais de saúde não-indígenas tratam assim de um universo simbólico completamente distinto do seu próprio, um universo em que relações são mais importantes que os termos isolados que as constituem. Desde o início, para os Wapichana e os Macuxi, a vida humana é concebida de modo singular e relacional. Assim, a existência de um filho é um fenômeno que antecede e ultrapassa o momento do parto. Já na gravidez, a mulher deve obedecer a algumas restrições, como não dormir ou comer em excesso, para evitar problemas durante o parto; precisa ainda evitar se aproximar de certas plantas, para não matá-las.

Após o parto, a mãe e o pai devem cumprir resguardo em benefício do filho. Idealmente, o resguardo de parto estende-se ao grupo dos consanguíneos próximos de ego (que são os avós paternos e maternos, os irmãos e as irmãs dos pais, e os irmãos maiores do recém-nascido), e tem a duração de dois anos ou mais. Porém, na prática, devido às dificuldades enfrentadas atualmente pelos Wapichana e os Macuxi, num contexto de inserção precária na economia regional e da percepção de enfraquecimento relativo dos laços de solidariedade aldeã, o grupo de consanguíneos evita apenas aqueles atos considerados mais nocivos para o recém-nascido, como matar cobras grandes ou encher pneus, durante alguns meses. De acordo com os indígenas, pai, mãe e filho devem necessariamente manter-se reclusos durante o período mínimo de uma semana após o nascimento, o tempo que leva para cair o cordão umbilical. Nesse ínterim, a mãe alimenta-se apenas de mingau de caridade (um caldo de mandioca insosso e morno) e não faz os serviços domésticos. O pai não deve realizar nenhum esforço físico, e o sexo é interdito a ambos.

O recém-nascido ainda não é exatamente uma pessoa. Ele é um ser frágil, especialmente exposto a uma série de perigos físicos e metafísicos, que merece atenção especial por parte daqueles com quem partilha o sangue, pois é vulnerável a todas as ações deles, especialmente àquilo que comem e aos movimentos que executam. Grosso modo, o recém-nascido é um ser que ainda não alcançou a condição huma- 
na plena, seu corpo caracteriza-se menos como uma etapa de fragilidade necessária e passageira do que como um estado de inacabamento problemático, e sua "alma" ainda não está plenamente ligada ao corpo; além disso, os laços que o unem à coletividade ainda terão de ser laboriosamente compostos.

As "aberturas" do corpo do recém-nascido são focos de grande cuidado e apreensão. Qualquer ação imprópria dos pais faz seu umbigo "boiar", rendendo-lhe uma hemorragia capaz de levá-lo à morte. Sua "moleira” é apontada como parte frágil, que deve ser protegida. Além disso, pelo orifício anal pode vir a sair o produto de uma digestão anômala, a diarreia. Seu ventre pode ainda estufar, em decorrência do contato dos pais com um cadáver. Se o pai, por exemplo, apertar um parafuso, o recém-nascido começará a se contorcer, como se seu próprio dorso estivesse sendo apertado; se a mãe ingerir um alimento reimoso, ${ }^{13}$ a criança terá diarreia, com o risco de vir a falecer. Entretanto, uma criança saudável traz muita alegria para todos os parentes, que já sabem reconhecer nela as preferências e os traços de personalidade.

Disto tudo se deduz que, entre os Wapichana e os Macuxi, a constituição da pessoa é correlata da instituição dos laços de parentesco. As práticas de resguardo sugerem, portanto, que o filho cria o pai e a mãe, na medida em que, após o parto, os pais devem demonstrar responsabilidade pelo filho, abstendo-se de alimentos e atividades que trariam sérios prejuízos ao bebê. Algumas pessoas me disseram que um pai pode fazer mal a seu filho mesmo que esteja "longe de casa", isto é, mesmo que não assuma o papel de pai social; de acordo com esta interpretação, o vínculo de sangue prevalece sobre o comportamento real dos genitores. Por outro lado, algumas pessoas afirmaram que a observação do resguardo pelos pais faz com que um filho adotivo tenha o mesmo status que um filho biológico. Percebe-se, assim, que várias possibilidades são contempladas pela lógica indígena, todas elas cifradas no idioma da substância.

\section{Políticas de saúde}

Diante do exposto, coloca-se a indagação: de que maneira este conjunto de ideias sobre pessoa, corpo, doença e saúde pode conviver com a "medicina do branco", que cada vez mais se faz presente nas aldeias em Roraima? Até o momento, o que se observa é a falta de entendimento entre as partes envolvidas na interação. Embora os indígenas reconheçam a importância da introdução de remédios industrializados e do hospital para dar conta de novas doenças, as divergências no que diz respeito a diagnósticos e a tratamentos são flagrantes. Creio que tais divergências ganham proporções preocupantes, na prática, devido à superioridade moral e téc- 
nica que a medicina ocidental se arroga.

Vimos que, entre os Wapichana e os Macuxi, assim como entre vários outros povos indígenas sul-americanos, o corpo - entendido como feixe de relações, estados e capacidades - é o centro da experiência humana, e que as práticas relativas à saúde são indissociáveis de uma determinada concepção de pessoa, exprimindo ainda um comentário político sobre o contato interétnico. A medicina alopática, por sua vez, tem como foco a doença em si, isto é, uma alteração negativa no corpo de um indivíduo, concebido como "paciente". Ao comparar a medicina ocidental a modos não-ocidentais de diagnóstico e tratamento de doenças, D. Hess (1995) destaca a concepção individualista daquela, que separa corpo e mente, tratando partes e sintomas isoladamente. No século XIX, conforme Chambers \& Gillespie (2000), o conjunto de técnicas e ideias da medicina alopática tornou-se hegemônico, alojando-se no seio do Estado; ao erigir-se como ciência, a medicina alopática concorreu para a deslegitimação de outros saberes sobre o corpo, os quais gradativamente passaram a ser concebidos como ilegítimos ou inferiores. ${ }^{14}$

A insensibilidade da razão médica ocidental a outros saberes sobre o corpo já foi alvo de inúmeras críticas, ao passo que técnicas “alternativas” como a acupuntura, a homeopatia e a medicina chinesa vêm ganhando cada vez mais espaço, o que não significa, entretanto, que as ideias centrais da medicina ocidental, decorrentes da cisão radical entre Natureza e Cultura, tenham sido alteradas. Nesse sentido, a determinação legal de um atendimento à saúde culturalmente diferenciado para os povos indígenas no Brasil, sob a responsabilidade do Estado, ainda não se transformou em prática.

O movimento indígena, por seu turno, tem dado provas de que cosmologia, afirmação da identidade étnica e luta por autonomia política andam de mãos dadas. Não é fortuita a recente eclosão, por todo o país, de organizações em prol do fortalecimento das práticas indígenas de cuidado da pessoa. No caso dos Baniwa, grupo de língua aruak que vive na região do Alto Rio Negro, por exemplo, L. Garnelo (2003) demonstrou que o processo de retomada da medicina tradicional está associado ao movimento de consolidação e proliferação de organizações políticas que visam à conquista da autonomia deste povo. Assim, o Projeto de Medicina Tradicional Baniwa, coordenado pela OIBI (Organização dos Indígenas da Bacia do Içana), tinha por objetivo recuperar as experiências dos antepassados, incluindo xamanismo e remédios tradicionais, e despertar nos jovens a consciência étnica (Garnelo, 2003:206).

Acredito que a inclusão dos elementos culturais que foram objeto deste estudo numa pauta de reflexão crítica sobre a medicina ocidental, em especial no âmbito da chamada "saúde indígena", pode garantir que os Wapichana, os Macuxi e tantos 
outros povos não se surpreendam, uma vez mais, ocupando uma posição subalterna na relação com o Estado brasileiro. Pois, para povos que concebem a ação social como o critério que distingue a pessoa tanto dos mortos como dos seres "sobrenaturais", ter acesso a vacinas e pílulas é tão importante quanto ver respeitadas as relações que compõem seus corpos.

\section{Notas}

1. Os dados etnográficos aqui apresentados foram reunidos no ano de 2003 na aldeia Pium, situada na Terra Indígena homônima, na "etnorregião" do Taiano, área de campos naturais ou lavrado, na margem direita do rio Uraricoera, afluente do Branco, distante cerca de 100km da capital de Roraima, Boa Vista. No Pium vivem indígenas das etnias Wapichana, Macuxi e Sapará; à época da pesquisa, a população era de 267 pessoas, habitando 30 casas. A aldeia é sede do polo-base da "etnorregião" do Taiano, acolhe as assembleias de tuxauas regionais e os cursos de formação de agentes indígenas de saúde, bem como realiza as festas mais concorridas de toda a "etnorregião" (Tempesta 2004). A língua mais falada na aldeia é a portuguesa. Os indígenas são unânimes em afirmar que aquela é uma região de ocupação predominantemente wapichana; nas duas últimas décadas, porém, intensificou-se o fluxo migratório macuxi proveniente das "serras".

2. O resguardo de parto é um tema clássico na etnologia indígena sul-americana. Para compilações a partir de diferentes perspectivas teóricas, ver P. Menget (1979), A. Métraux (1963) e P. Rivière (1974), entre outros.

3. Um exemplo disso é a notícia de que, recentemente, 10 hospitais públicos de São Paulo começaram a se adaptar às tradições guarani, modificando o cardápio do resguardo de parto para atender às mães indígenas e, assim, tentar diminuir as taxas de mortalidade infantil indígena (O Estado de São Paulo, 18/08/08, Caderno Vida, p. A20).

4. Consultar N. Farage (1991) para a história da colonização do vale do rio Branco e as relações entre povos indígenas, portugueses, holandeses e ingleses no século XVIII. Sobre a relação dos Wapichana, Macuxi, Sapará, Ingarikó, Patamona e Taurepang com as agências republicanas, ver P. Santilli (1994 e 2001; Farage \& Santilli, 1992). Para dados sobre organização social, território e concepções de saúde num viés culturalista, consultar respectivamente L. Herrmann (1946), O. Sampaio e Silva (1980) e G. Mussolini (1944).

5. Como é de praxe, os nomes verdadeiros dos indígenas foram substituídos por nomes fictícios.

6. Para uma análise detalhada sobre os panaokarunao, ver N. Farage (1997). Esclareço que "bicho", enquanto sinônimo de "espírito", não se confunde com "animal", termo aplicado às espécies de mamíferos que vivem na mata e que podem ser caçados e consumidos.

7. Os Wapichana e os Macuxi dizem que é o sangue menstrual que forma o corpo dos 
bebês, no útero da mãe.

8. A panema é um fenômeno difundido por toda a região amazônica; para uma análise estrutural, ver R. DaMatta (1977).

9. Caxiri é uma bebida fermentada à base de mandioca.

10. "Alma" é o termo em português que os indígenas do Pium usam para se referir àquilo que dá vida, que anima a pessoa, similar ao conceito de anima em latim, compreendendo o batimento cardíaco, a disposição física para todas as atividades, a linguagem articulada, a pulsação e o sangue. As dimensões substantivas da "alma” permitem compreender que este conceito não se confunde com o conceito ocidental de alma, que se opõe a corpo.

11. À presente análise da vida social dos Wapichana e Macuxi aplicam-se vários insights de P. Gow $(1991,1997,2000)$ a respeito das populações nativas do Baixo Urubamba, na Amazônia peruana.

12. Os teóricos alinhados com a "antropologia do cotidiano" dialogam com M. Mauss (1974a, 1974b) a respeito da noção de pessoa e das técnicas corporais, mas, em vez de analisarem a forma como as sociedades modelam o corpo humano, propõem pensar a construção do social pela via da corporalidade.

13. "Reimoso" é uma categoria alimentar disseminada na Amazônia, que se refere ao alimento "pesado", que faz mal a uma pessoa em estado delicado de saúde, mas que, em condições normais, dá força e ânimo para as atividades cotidianas, assim como é fonte de prazer. Os Wapichana e Macuxi incluem nesta categoria peixes "de pele" (grandes, com muito sangue), certas carnes de caça e de porco doméstico e caxiri, entre outros alimentos. Para uma comparação com um contexto ribeirinho amazônico, ver Maués \& Maués (1973).

14. Certamente o discurso médico não é homogêneo, mas não há espaço aqui para discorrer sobre suas nuances e contradições internas. Gostaria apenas de sublinhar o caráter assimétrico da relação entre medicina ocidental e medicina indígena a partir de um estudo de caso. 


\section{Referências bibliográficas}

CHAMBERS, D.W. \& GILLESPIE, R. 2000. "Locality in the history of science: colonial science, technoscience and indigenous knowledge”. OSIRIS, vol. 15.

DAMATTA, Roberto. 1977. "Panema: uma tentativa de análise estrutural”. In: . Ensaios de Antropologia Estrutural. Petrópolis: Vozes. pp. 67-96.

DOUGLAS, Mary. 1966. Purity and Danger. Inglaterra: Penguin Books.

FARAGE, Nádia. 1991. As Muralhas dos Sertões - os povos indígenas no Rio Branco e a colonização. Rio de Janeiro: Paz e Terra/ANPOCS.

1997. As flores da fala: práticas retóricas entre osWapishana. Tese de doutorado inédita, Programa de Pós-Graduação em Letras, FFLCH-USP.

\& SANTILLI, Paulo. 1992. "Estado de sítio. Territórios e identidades no vale do rio Branco”. In: Manuela Carneiro da Cunha (org.). História dos Índios no Brasil. São Paulo: Cia. Das Letras/Fapesp. pp. 267-278.

FAUSTO, Carlos. 2002. "Banquete de gente: comensalidade e canibalismo na Amazônia”. Mana 8 (2):7-44.

FOLLÉR, Maj-Lis. 2004. "Intermedicalidade: a zona de contato criada por povos indígenas e profissionais de saúde”. In: Esther Jean Langdon \& Luiza Garnelo, (orgs.). Saúde dos Povos Indígenas: reflexões sobre antropologia participativa. Rio de Janeiro: Contra Capa Livraria/ABA. pp. 129-147.

FORTE, Janette. 1990. "The Populations of Guyanese Amerindian Settlements in the 1980s". In: Occasional Publications of the Amerindian Research Unit. Georgetown: University of Guyana.

GARNELO, Luiza. 2003. Poder, Hierarquia e Reciprocidade: saúde e harmonia entre os Baniwa do Alto Rio Negro. Rio de Janeiro: Fiocruz.

GOW, Peter. 1991. Of Mixed Blood. Kinship and history in Peruvian Amazonia. Oxford: Claredon Press. 
. 1997. "O parentesco como consciência humana: o caso dos Piro". Mana 3(2):39-65.

2000. "Helpless - the affective preconditions of Piro social life". In: Joanna Overing \& Alan Passes (orgs.). The anthropology of love and anger-the aesthetics of conviviality in Native Amazônia. London and New York: Routledge. pp. 46-63.

HERRMANN, Lucila. 1946a. "Organização social dos Vapidiana do território do rio Branco”. Sociologia, vol. VIII, n. 3:282-304; 1946b. "Organização social dos Vapidiana do território do rio Branco” (continuação). Sociologia, vol. VIII, n. 4:203-215.

HESS, David. 1995. "Other ways of knowing and doing: the ethnoknowledges and non-western medicines”. In: . Science and technology in a multicultural world: the cultural politics of facts and artifacts. Nova York: Columbia University Press. pp. 185-210.

MAUÉS, Raimundo Heraldo \& MOTTA MAUÉS, Maria Angélica. 1973. “O modelo da reima: representações alimentares em uma comunidade amazônica”. Anuário Antropológico, 77:120-147.

MAUSS, Marcel. 1974. a) "Uma categoria do espírito humano: a noção de pessoa, a noção do 'eu”"; b) “As técnicas corporais”. In: . Sociologia e Antropologia. São Paulo: EPU/ Edusp. vol. I, pp. 207-241; vol. II, pp. 209-233.

MCCALLUM, Cecilia. 1998. "Alteridade e sociabilidade Kaxinauá: perspectivas de uma antropologia da vida diária”. Revista Brasileira de Ciências Sociais, vol. 13, n. 38:127-136.

MENGET, Patrick. 1979. "Temps de nâitre, temps d'être: la couvade”. In: Michel Izard \& Pierre Smith (eds.). La Fonction Symbolique. Paris: Gallimard. pp. 245-264.

MÉTRAUX, Alfred. 1963. "The couvades”. In: Julian Steward. Hanbook of South American Indians. vol. 5. Nova York: Cooper Square Publishers. pp. 369-374.

MUSSOLINI, Gioconda. 1944. Notas sobre os conceitos de moléstia, cura e morte entre os índios Vapidiana. Sociologia, vol. VI, n. 2:134-155. 
OVERING, Joanna \& PASSES, Alan (orgs.). 2000. The anthropology of love and anger - the aesthetics of conviviality in Native Amazônia. London and New York: Routledge.

RICARDO, Carlos Alberto (ed.). 2006. Povos Indígenas no Brasil, 2001-2006. São Paulo: Instituto Socioambiental. pp. 300-332.

RIVIÈRE, Peter. 1974. “The Couvade: a problem reborn”. Man, 9 (3):423-435.

SAMPAIO E SILVA, Orlando. 1980. "Os grupos tribais do território de Roraima”. Revista de Antropologia, XXIII:69-89.

SANTILLI, Paulo. 1994. As Fronteiras da República. História e Política entre os Macuxi no vale do Rio Branco. São Paulo: NHII/USP/Fapesp.

2001. Pemongon Patá: território Macuxi, rotas de conflito. São Paulo: Editora Unesp.

. 2002. "Trabalho escravo e brancos canibais. Uma narrativa histórica Macuxi”. In: Bruce Albert \& Alcida Ramos (orgs.). Pacificando o Branco: cosmologias do contato no Norte-Amazônico. São Paulo: Editora Unesp/ Imprensa Oficial do Estado. pp. 487-505.

STRATHERN, Marilyn. 1995. "Necessidade de pais, necessidade de mães”. Estudos feministas, n. 2:303-329.

. 1997. "Entre uma melanesianista e uma feminista". Cadernos Pagu, 8/9:7-49.

TEMPESTA, Giovana A. 2004. A produção continuada dos corpos. Práticas de resguardo entre os Wapichana e os Macuxi em Roraima. Dissertação de mestrado inédita, Unicamp, Campinas.

VIVEIROS DE CASTRO, Eduardo. 2002. "Perspectivismo e multinaturalismo na América indígena”. In: - A Inconstância da Alma Selvagem e Outros Ensaios de Antropologia. São Paulo: Cosac \& Naify. pp. 345-399. 


\section{Resumo}

O presente artigo focaliza as noções de pessoa, corpo, saúde e doença desenvolvidas pelos Wapichana e Macuxi no leste de Roraima. De acordo com esta cosmologia, a formação da pessoa é um processo continuado, simultâneo à constituição de laços sociais e ameaçado tanto por agências humanas quanto por agências não-humanas e extra-humanas, como os "bichos" e "kanaimés”, que causam doenças e malefícios aos homens. Os modos tradicionais de evitar e combater esses perigos são os resguardos e o xamanismo, os quais, no presente, experimentam uma convivência difícil com o sistema de saúde estatal, uma convivência que pode vir a se transformar em um diálogo intercultural, com o apoio dos antropólogos, desde que se respeite o projeto de autonomia dos povos indígenas.

\section{Palavras-chave}

Wapichana, Macuxi, Pessoa, Corpo, Saúde, Doença

\begin{abstract}
This article considers ideas about person, body, health and disease developed by the Wapichana and the Macuxi living in the east portion of the State of Roraima, Brazil. In this cosmology the continuous process of personhood construction, which is simultaneous to the constitution of social ties, is threatened by human, not human and extra human agencies, such as the "bichos" and the "kanaimé", which bring diseases and harm to the people. The traditional ways to avoid and to fight against these dangers are the "resguardos" and the shamanism, which today have a difficult coexistence with the governmental health system; this coexistence may become an intercultural dialogue, with the help of anthropologists, as long as the project of autonomy of indigenous peoples is respected.
\end{abstract}

\section{Key words}

Wapichana, Macuxi, Person, Body, Health, Disease 